\title{
Microstructure and Conductivity of the Al-Cu Joint Processed by Friction Stir Welding
}

\author{
Yanni Wei $\mathbb{D}^{1,2}$ Hui Li, ${ }^{2}$ Peng Xiao, ${ }^{1,2}$ and Juntao Zou ${ }^{1,2}$ \\ ${ }^{1}$ Shaanxi Province Key Laboratory for Electrical Materials and Infiltration Technology, Xi'an University of Technology, Xi'an, \\ Shaanxi 710048, China \\ ${ }^{2}$ Department of Materials Science and Engineering, Xi'an University of Technology, Xi'an 710048, China
}

Correspondence should be addressed to Yanni Wei; weiyanni@xaut.edu.cn

Received 23 April 2020; Revised 9 June 2020; Accepted 26 June 2020; Published 27 July 2020

Academic Editor: Stefano Bellucci

Copyright (c) 2020 Yanni Wei et al. This is an open access article distributed under the Creative Commons Attribution License, which permits unrestricted use, distribution, and reproduction in any medium, provided the original work is properly cited.

In this paper, 1060 aluminum and T2 pure copper were joined by friction stir welding. The influence of the rotation speed and inclination on the microstructure and mechanical properties of the joint were investigated. The microstructure and composition of the welded interface region were analyzed. The joints' strength was tested, and the conductivity of the joints was estimated. Joints having good surface formation and defect-free cross section were successfully obtained. The cross-sectional morphologies of the $\mathrm{Al}-\mathrm{Cu}$ friction stir welding joints can be divided into three zones: the shoulder impact zone, the weld nugget zone, and the interface zone. The interface zone consisted of a metallurgical reaction layer and a visible mixed structure. The reaction layers were identified as $\mathrm{Al}_{2} \mathrm{Cu}, \mathrm{Al}_{4} \mathrm{Cu}_{9}$ phases. The tensile strength of the joints reaches maximum values of $102 \mathrm{MPa}$ at a rotation speed of $950 \mathrm{rpm}$ and inclination of $0^{\circ}$, which was approximately equal to those of $1060 \mathrm{Al}$ base metal. The resistivity of the $\mathrm{Al}-\mathrm{Cu}$ joint was approximately equal to the theoretical resistivity. The interfacial resistance is directly affected by the joint defects, compound types, and thickness of the intermetallic compound layer.

\section{Introduction}

$\mathrm{Al}-\mathrm{Cu}$ bimetallic composites structures can realize the combination of the light weight and the corrosion resistance properties of $\mathrm{Al}$ and the high electrical conductivity, high thermal conductivity, and low contact resistance of $\mathrm{Cu}[1-3]$. These structures have been used in the power transmission, refrigeration, and hydrometallurgy and others fields, such as bus-bars, electrical connectors, and heat-exchangers tubes [4-6]. However, the aluminum oxide film and the intermetallic compounds (IMCs) are unavoidable in $\mathrm{Al}-\mathrm{Cu}$ joint in view of their metallurgical characteristics [7]. The oxide film prevents the direct contact between $\mathrm{Cu}$ and $\mathrm{Al}$ [8]. The thick Al-Cu IMCs can severely degrade the joint performance [9].

Friction stir welding (FSW), as a solid phase pressure welding method, is a revolutionary joining process patented by the Welding Institute (TWI) [10] which is an effective way of joining heterogeneous materials that weld poorly using fusion. During the FSW process, the rotating stir tool was inserted into the prejoining surface. The material near the stir tool were plasticized by the friction heat and forced to mix with each other [11]. At present, FSW has successfully achieved heterogeneous metals such as Al-Mg [12, 13], AlSteel [14, 15], Al-Ti [16], and Al-Cu [17-23]. A large number of related researches on Al-Cu FSW joints have been carried out. The investigation is mainly aimed at the effects of the parameters on microstructure, performance of joints [17-20], and formation mechanism of the interface IMCs [21-23]. In $[18,19]$, the influence of plate position, rotational speed, and offset on mechanical properties and microstructures of the Al-Cu FSW joints is studied. And, they indicated that the increase in rotation speed promotes the thickening of the IMCs. The study on the temperature field distribution and the evolution of IMCs showed that solid phase transformation and solidification transformation were the main formation mechanisms of IMCs [21]. Beygi et al. [23] found the threaded conical tool provided the best 
compromise between the different material flow regions. Although a large number of related researches on $\mathrm{Al}-\mathrm{Cu}$ FSW joints have been carried out, there are relatively few studies on the conductivity of the joints. The 1060 aluminum alloy has the most potential as a substitute for copper materials as conductive components in power transmission systems (such as $\mathrm{Al}-\mathrm{Cu}$ wires and $\mathrm{Al}-\mathrm{Cu}$ conductive bars). It is of great significance to study the microstructure and its relationship with the strength and conductivity of the 1060Al-T2Cu FSW joint.

Since $\mathrm{Cu}$ and $\mathrm{Al}$ are good conductive materials, the conductivity of the interfacial layer is the key to determine the overall conductivity of the Al-Cu bimetallic composite structures. Therefore, this paper focuses on the interface microstructure and its influence on joint strength and conductivity of the 1060Al-T2Cu FSW joint. The FSW method was used to weld $4 \mathrm{~mm} 1060$ aluminum alloy and T2 copper. The influence of welding parameter on the microstructure, mechanical properties, and electrical conductivity of the joint was investigated. It is expected to provide certain theoretical and data support for the use of $1060 \mathrm{Al}-\mathrm{Cu}$ composite components in the field of conduction.

\section{Experimental Procedure}

Commercially pure aluminum alloy 1060 plate and T2 copper plate with $4 \mathrm{~mm}$ in thickness were selected for the experiment. The schematic diagram of the Al-Cu FSW processes and the stir tool are shown in Figure 1. The FSW experiment was conducted using a modified XA5032 vertical milling machine with homemade fixtures for welding. The welding method was a single-pass butt, with the copper plate placed on the advancing side (AS) and the aluminum plate placed on the retreating side (RS), as shown in Figure 1(a). The stir tool was made of W18Cr4V high-speed steel with a columnar shaped shoulder and a screw thread tapered pin (size: root: $\Phi 7 \mathrm{~mm}$, tip: $\Phi 4 \mathrm{~mm}$, and length: $3.8 \mathrm{~mm}$ ), as shown in Figure 1(b). During the welding process, the stir tool clockwise rotation, the offset toward to $\mathrm{Al}$ metal was $1 \mathrm{~mm}$, the welding speed was $60 \mathrm{~mm} / \mathrm{min}$, and the rotation speed was 750 1500 rpm. The experimental parameters are shown in Table 1.

The welded samples for metallographic examination were cut perpendicular to the welding interface. The microstructure was analyzed by optical microscopy (OM) and scanning electron microscopy (SEM, JEOL, JSM-6700) equipped with an energy-dispersive spectrum (EDS). The mechanical properties of the joints were evaluated by tensile tests (Instron 5880). The tukon-2100 microdimension hardness tester was used to test the interface microhardness with a load of $10 \mathrm{~g}$ and a holding time of $10 \mathrm{~s}$. The electrical resistance of the joints was tested by microohmmeter (TEGAM1750).

\section{Results and Discussion}

3.1. Weld Surface Morphology of Al-Cu FSW Joint. The morphology of the weld surface produced by different parameters is shown in Figure 2. The weld surface of FSW was composed of a series of arc curve and the keyhole left by the stir pin. Due to the friction and extrusion of the shoulder, obvious burrs were formed on both sides of the weld surface. At the rotation speed of $750 \mathrm{rpm}$, groove-shaped defects appeared, as shown in Figure 2(a). During the FSW process, the surface groove-type defect often appears on the upper surface of the FSW weld when the welding heat input was insufficient. The thermoplastic metal around the stir tool is insufficient, and the plastic metal cannot fully fill the instantaneous cavity left during the course of the stirring pin, thereby forming a surface groove near the advancing edge. The weld surface was well formed, and the circular ring lines were uniform when the rotation speed was $950 \mathrm{rpm}$ and $1180 \mathrm{rpm}$. Regional accumulation and poor uniformity appeared in the weld surface when the rotation speed was $1500 \mathrm{rpm}$, indicating that the flow of plastic metal fluctuated during the welding process, as shown in Figure 2(d). After adding the stir tool inclination, a rough weld surface (as shown in Figures 2(e) and 2(f)) was formed due to the increases in the downward pressure behind the shoulder of the tool. The rough weld surface was mainly made up of some Al filaments.

\subsection{Microstructure of Al-Cu FSW Joint}

3.2.1. Cross-Sectional Morphologies. Figure 3 shows the typical cross-sectional morphologies and the regional characteristics of the Al-Cu FSW joints. Figure 3(a) is the overall cross-sectional view of the joint. The entire weld can be divided into three regions: the shoulder impact zone, the weld nugget zone, and the interface zone, as shown by the oval red dotted line in Figure 3(a). The plasticized material shows two flow states in the cross section. The upper part of the weld shows parallel flow, while the bottom shows a circular flow. The material flow in the upper part of the weld depends mainly on the drive of the shoulder. Moreover, the heat input in the upper part of the weld was sufficient and the material was plasticized adequately, and the copper strip peeled off and migrated farther. On the contrary, the material flow was mainly driven by the stir pin in the middle and lower parts of the weld. Accompanied by the upper and lower annular vortices due to the screw thread tapered pin, the circular flow played an important role in the middle and lower parts of the weld.

Figures $3(\mathrm{~b})-3(\mathrm{~d})$ are the morphology of the advancing side of the weld. During the FSW process, the stir tool rotated rapidly to peel off a large amount of copper particles. These particles were softened, fragmented, and flowed by the friction and stir effect of the stir tool and dispersed in the aluminum matrix. A gray matter was formed near the larger $\mathrm{Cu}$ particle edges, as shown in Figure 3(b). It indicated that metallurgical bonding occurred between these copper particle and aluminum. The reaction occurred along the Al-Cu interface, and layered compounds were formed on the interface, as shown in Figure 3(c). The copper particles were continuously stretched and formed alternating the layered structure, as shown in Figures 3(d)-3(d). EDS analysis of these compounds was shown in Table 2. The results showed that these phases were likely to be $\mathrm{AlCu}, \mathrm{Al}_{2} \mathrm{Cu}$, and $\mathrm{Al}_{4} \mathrm{Cu}_{9}$ phases. 


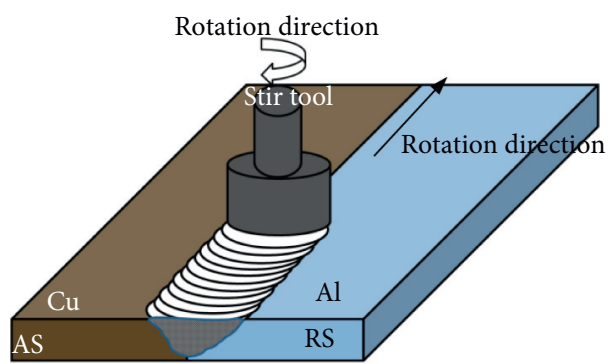

(a)

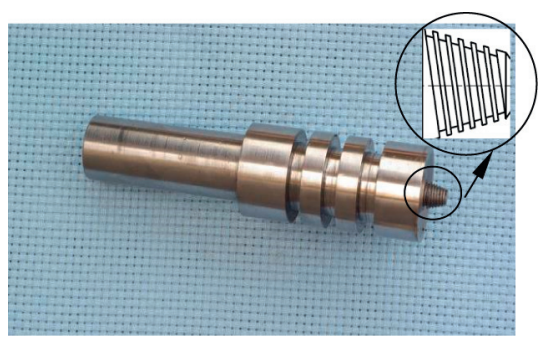

(b)

FIgURE 1: Experimental setup: (a) the schematic diagram of FSW process and (b) the stir tool.

TABle 1: The experimental parameters of the Al-Cu FSW process.

\begin{tabular}{lccc}
\hline Samples & Rotation speed $n(\mathrm{rpm})$ & Welding speed $v\left(\mathrm{~mm} \cdot \mathrm{min}^{-1}\right)$ & Inclination $\theta\left(^{\circ}\right)$ \\
\hline 1 & 750 & 60 & 0 \\
2 & 950 & 60 & 0 \\
3 & 1180 & 60 & 0 \\
4 & 1500 & 60 & 0 \\
5 & 950 & 60 & 2 \\
6 & 1180 & 60 & 2 \\
\hline
\end{tabular}

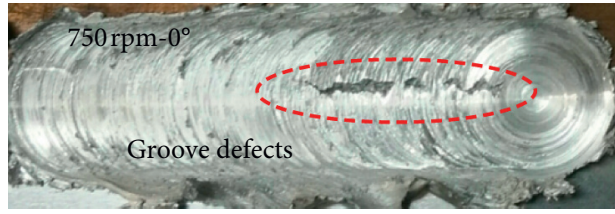

(a)

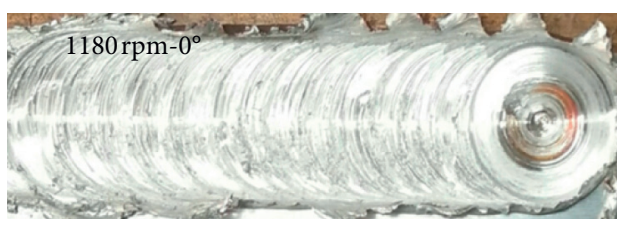

(c)



(e)

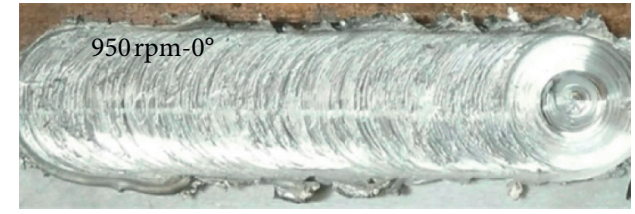

(b)

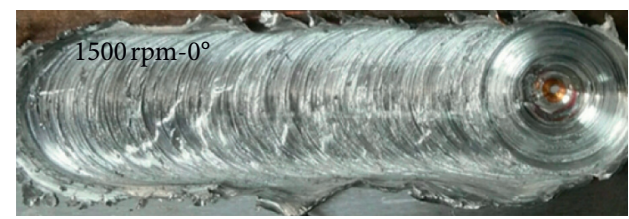

(d)



(f)

Figure 2: The weld surface morphology of Al-Cu FSW joint produced by (a) $750 \mathrm{rpm}-0^{\circ}$, (b) $950 \mathrm{rpm}-0^{\circ}$, (c) $1180 \mathrm{rpm}-0^{\circ}$, (d) $1500 \mathrm{rpm}-0^{\circ}$, (e) $950 \mathrm{rpm}-2^{\circ}$, and (f) $1180 \mathrm{rpm}-2^{\circ}$.

These phases were further determined by XRD analyses. In this experiment, the thickness of the intermetallic compound layer at the $\mathrm{Al} / \mathrm{Cu}$ interface of FSW joints was within the range of $0.3 \sim 2.7 \mu \mathrm{m}$, which was different according to the welding parameters and the test position. The maximum thickness of the intermetallic layer is not more than $3 \mu \mathrm{m}$.

3.2.2. Interfacial Diffusion in the Al-Cu FSW Joint. Figure 4 shows a SEM image of interface layer of the $\mathrm{Al}-\mathrm{Cu}$ FSW joint produced by different parameters. An obvious
IMCs layer was formed on the $\mathrm{Al}-\mathrm{Cu}$ interface, which indicated that the metallurgical reaction occurred during the friction stir welding process. In order to compare the thickness of the reaction layers obtained under different parameters, the microstructure shown in Figure 4 was tested at the same position of different samples (on the $\mathrm{Al}-\mathrm{Cu}$ interface near the bottom of the weld). As the rotation speed increases from $750 \mathrm{rpm}$ to $1500 \mathrm{rpm}$, the thickness of the interface reaction layer was increased from $0.38 \mu \mathrm{m}$ to $0.91 \mu \mathrm{m}$. The thickness of the reaction layer was positively correlated with the rotation speed. Schmidt et al. [24] pointed 


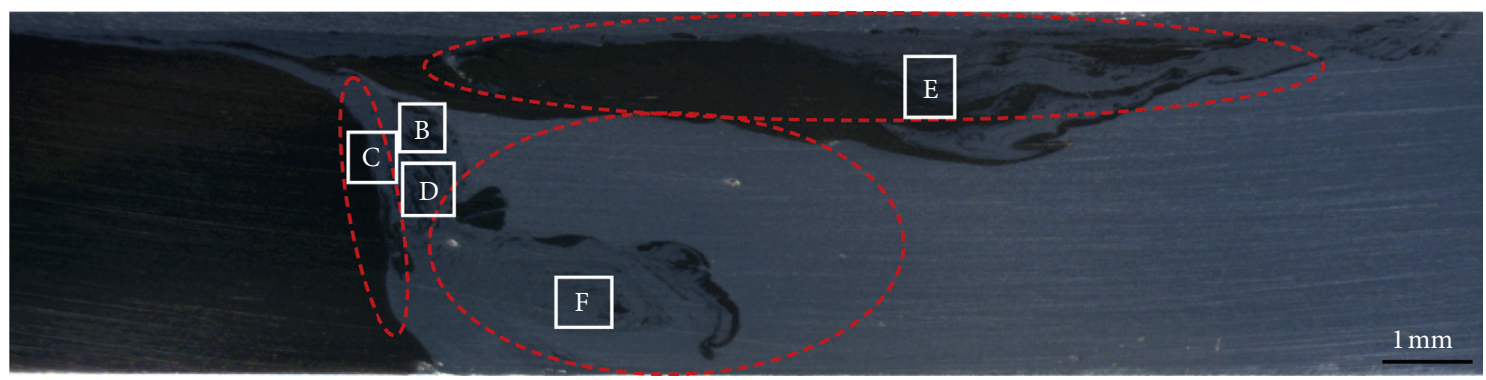

(a)

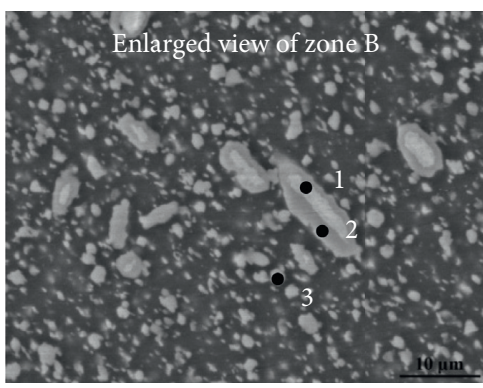

(b)



(e)



(c)

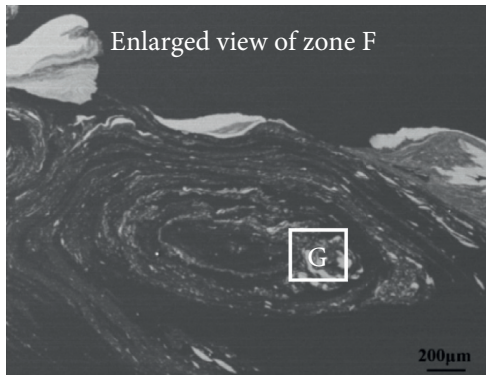

(f)

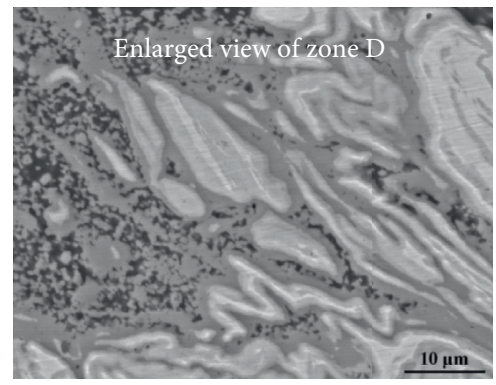

(d)

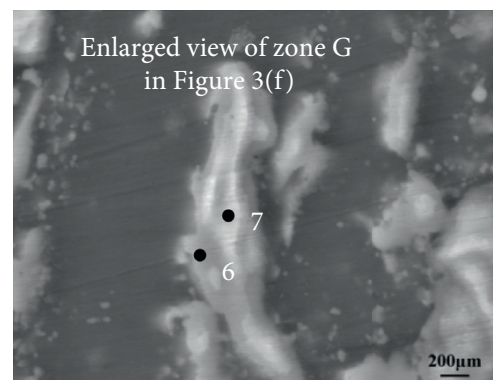

(g)

FIgURE 3: The cross-sectional morphologies and the regional characteristics of the Al-Cu FSW joints.

TABLE 2: EDS point analysis results of location in Figure 3.

\begin{tabular}{lccc}
\hline Points & $\mathrm{Al} \mathrm{(at \% )}$ & $\mathrm{Cu}($ at\%) & Phase speculation \\
\hline 1 & 47.77 & 52.23 & $\mathrm{AlCu}$ \\
2 & 66.50 & 33.50 & $\mathrm{Al}_{2} \mathrm{Cu}$ \\
3 & 80.84 & 19.16 & $\mathrm{Al}+\mathrm{IMC}$ \\
4 & 49.14 & 50.86 & $\mathrm{AlCu}$ \\
5 & 71.36 & 28.64 & $\mathrm{Al}_{2} \mathrm{Cu}$ \\
6 & 63.84 & 36.16 & $\mathrm{Al}_{2} \mathrm{Cu}$ \\
7 & 28.61 & 71.39 & $\mathrm{Al}_{4} \mathrm{Cu}_{9}$ \\
\hline
\end{tabular}

out that the heat mainly comes from the friction between the shoulder and the stir pin and the base metal. The welding heat input was proportional to the rotation speed. This leads to a thicker diffusion layer when there was a high rotation speed. Researches show that the thickness of the metallurgical reaction layer was related to the mechanical properties of the joint. Xue et al. [25] and Abbasi et al. [26] pointed out that the formation of thin, continuous, uniform IMCs was a necessary condition for a good metallurgical bond. But, the thickness of the interfacial diffusion layer should be less than $2.5 \mu \mathrm{m}$. It indicated that the thickness of the metallurgical reaction layer in this experiment could obtain good bonding strength.
Figure 5 shows the distribution of elements that are perpendicular to the interface (denoted by the yellow line in Figure 5(a)) and the elemental surface distribution. It could be found that the content of $\mathrm{Al}$ and $\mathrm{Cu}$ elements were changed, consistent with the change of microstructure, as shown in Figure 5(c). In the alternating layered structure of $\mathrm{Al}$ and $\mathrm{Cu}$, the fluctuation of diffraction intensity of $\mathrm{Al}$ and $\mathrm{Cu}$ is mainly related to the distribution pattern of both. And, the corresponding width of the alternating layers is shown in Figure 5(c). Image plane scanning analysis results of $\mathrm{Al}$ and $\mathrm{Cu}$ distributions are shown in Figures 5(d) and 5(b), respectively. The element 


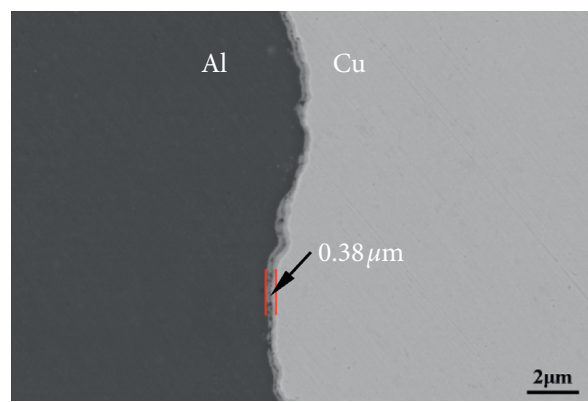

(a)

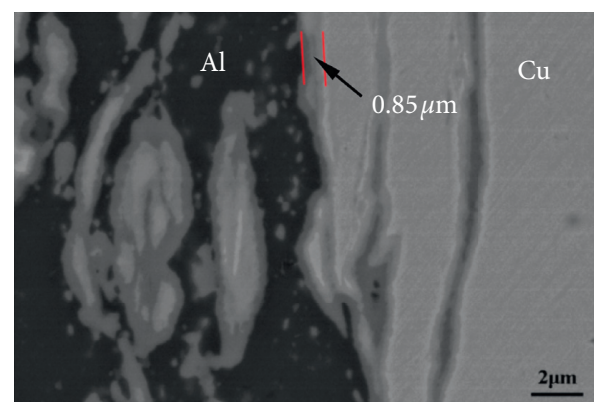

(c)

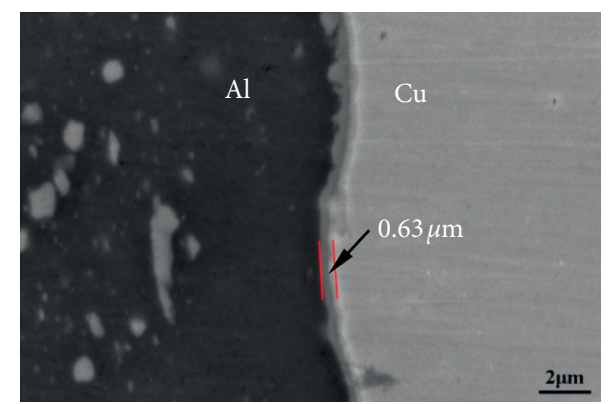

(b)

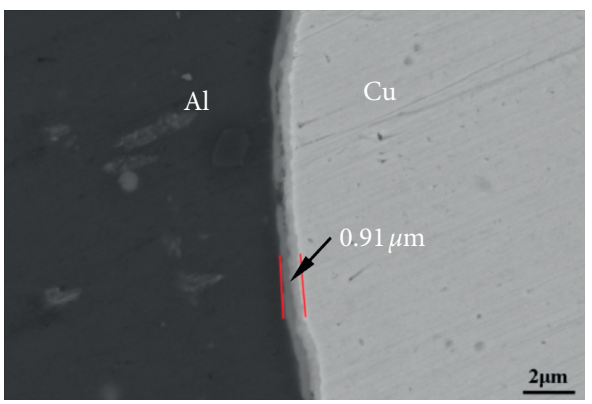

(d)

FIgURE 4: The SEM image of interface layer of the Al-Cu FSW joint produced by (a) $750 \mathrm{rpm}-0^{\circ}$, (b) $950 \mathrm{rpm}-0^{\circ}$, (c) $1180 \mathrm{rpm}-0^{\circ}$, and (d) $1500 \mathrm{rpm}-0^{\circ}$.

distribution of the $\mathrm{Al}-\mathrm{Cu}$ interface region is shown more clearly.

\subsection{Performance of the Al-Cu FSW Joint}

3.3.1. Mechanical Property of the Al-Cu FSW Joint. Figure 6 shows the tensile strength of the joints and the typical stress-strain curves. The joint strength increases with the rotation speed and reaches a maximum value at $950 \mathrm{rpm}$, and then decreasing behavior appears. The maximum can reach to $102 \mathrm{MPa}$, which is approximately equal to that of $1060 \mathrm{Al}$ base metal. When the inclination is increased, the strength of the joint is slightly reduced when the inclination was employed. The strength of the joint depends on the macroscopic forming and microstructure of the weld. At low rotation speed, insufficient heat input in the weld area was likely to lead to surface groove defects, so the joint strength was low. However, when the rotation speed was higher, weld overheating would lead to defects such as surface peeling or filaments. At the same time, more interfacial compounds were formed. Experiments showed that higher joint strength was obtained when the rotation speed was $950 \mathrm{rpm}$ due to its proper heat input. The mechanism of joining can be attributed to the combination of mechanical bonding and metallurgical bonding, which has been reported by Esmaeili et al. [27]. An interlaced structure and the $\mathrm{Cu}$ scrapings near the interface provide mechanical bonding effect. The metallurgical bonding was achieved depending on the atomic diffusion and the $\mathrm{Al}-\mathrm{Cu}$ chemical reaction.

The fracture morphology of the joints is shown in Figure 7 . The fracture of the joint produced by a rotation speed of $750 \mathrm{rpm}$ was composed of dimples of different sizes, but the dimple was generally shallow, as shown in Figure $7(\mathrm{a})$. When the rotation speed increased to $950 \mathrm{rpm}$, as shown in Figure 7(b), the fracture was composed of a large area of the dimple zone and a small amount of cleavage zone. The fracture completely becomes a flat cleavage surface when the rotation speed was $1500 \mathrm{rpm}$, as shown in Figure 7(d). It indicated that the fracture mechanism of the joint changes from the original ductile-brittle mixed fracture to brittle fracture as the rotation speed increases, which is consistent with the tensile strength results obtained. In order to further confirm the IMCs on the Al-Cu interface, XRD analysis was performed on the tensile fracture of the joints. Figure 8 shows the $\mathrm{X}$-ray diffraction pattern of the cross section of the joint. In addition to the $\mathrm{Al}$ and $\mathrm{Cu}$ base metal, the diffraction peaks of the $\mathrm{Al}_{2} \mathrm{Cu}$ and $\mathrm{Al}_{4} \mathrm{Cu}_{9}$ compounds appeared. Compared with the results in the Table 2, the diffraction peak of the AlCu phase did not occur probably because its content was too small. It indicated that $\mathrm{Al}_{2} \mathrm{Cu}$ and $\mathrm{Al}_{4} \mathrm{Cu}_{9}$ phases were formed on the $\mathrm{Al}-\mathrm{Cu}$ interface during the FSW process, and the joint achieved a good metallurgical bonding. This was consistent with the compounds reported in [28].

Figure 9 shows the microhardness curve of the joints. The average hardness of the base $\mathrm{Al}$ and $\mathrm{Cu}$ was $39.3 \mathrm{HV}$ and $90.5 \mathrm{HV}$. The hardness of the weld zone is significantly higher than that of the base metal, and the hardness distribution was irregular. The heat-affected zone showed lower hardness due to the effect of the welding thermal cycle. With the increase of the rotation speed, the average hardness of the nugget zone increased slightly. The indentation of 


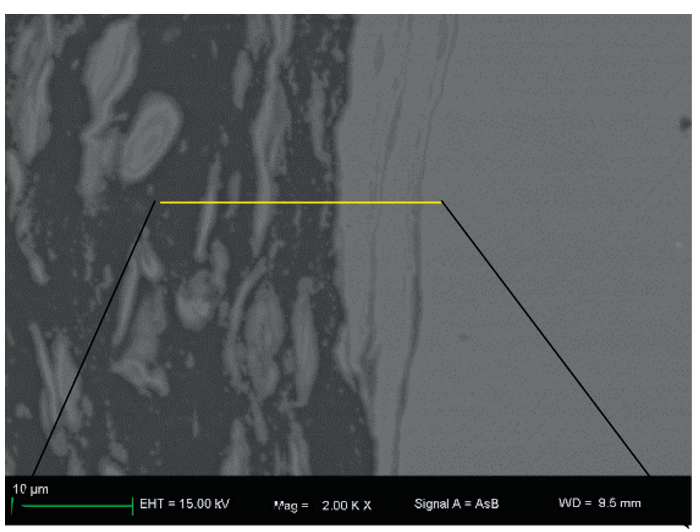

(a)

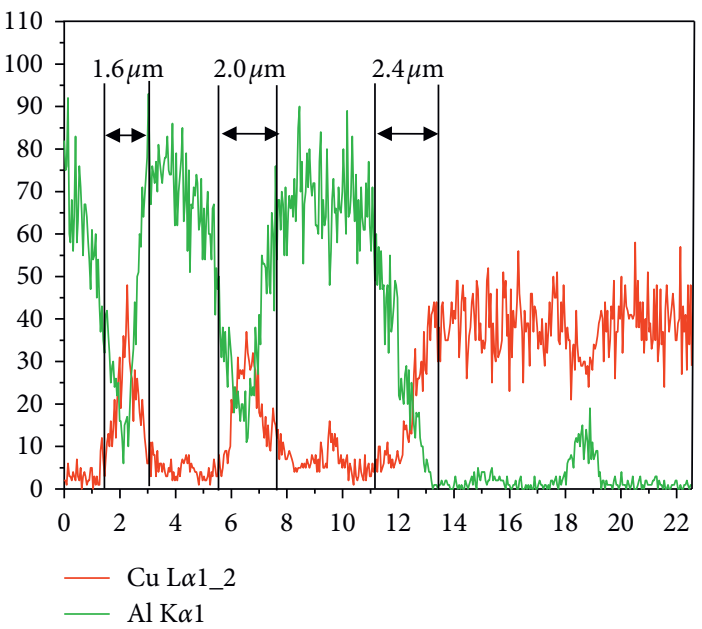

(c)

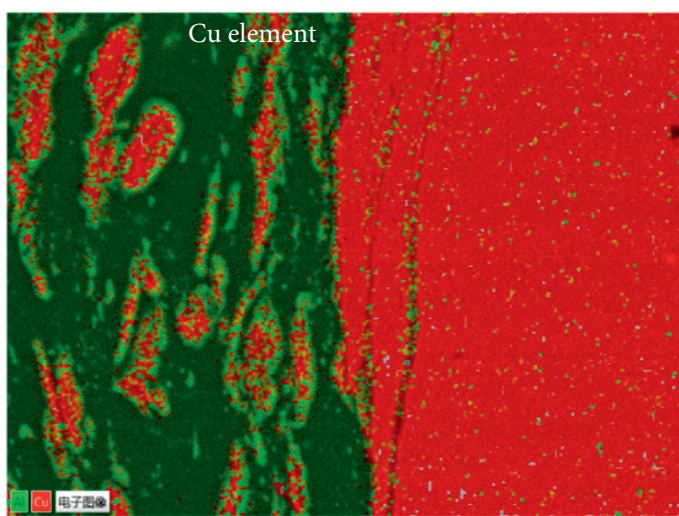

(b)

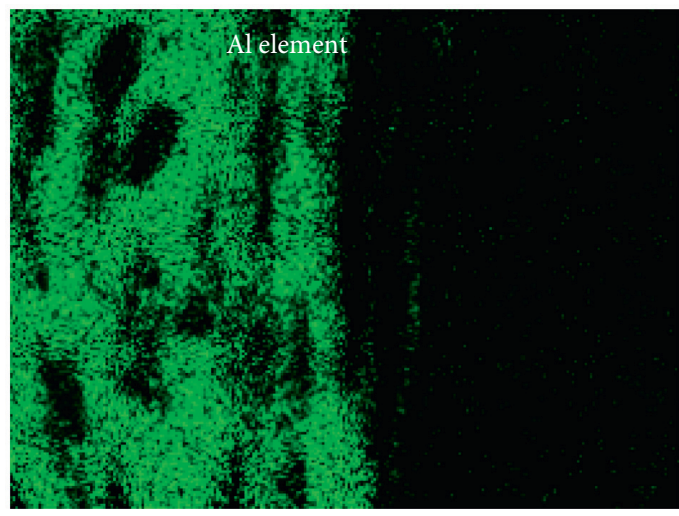

(d)

Figure 5: An interlaced structure on the Al-Cu interface: (a) interface feature, (b) Cu element distribution, (c) distribution of elements perpendicular to the interface, and (d) Al element distribution.

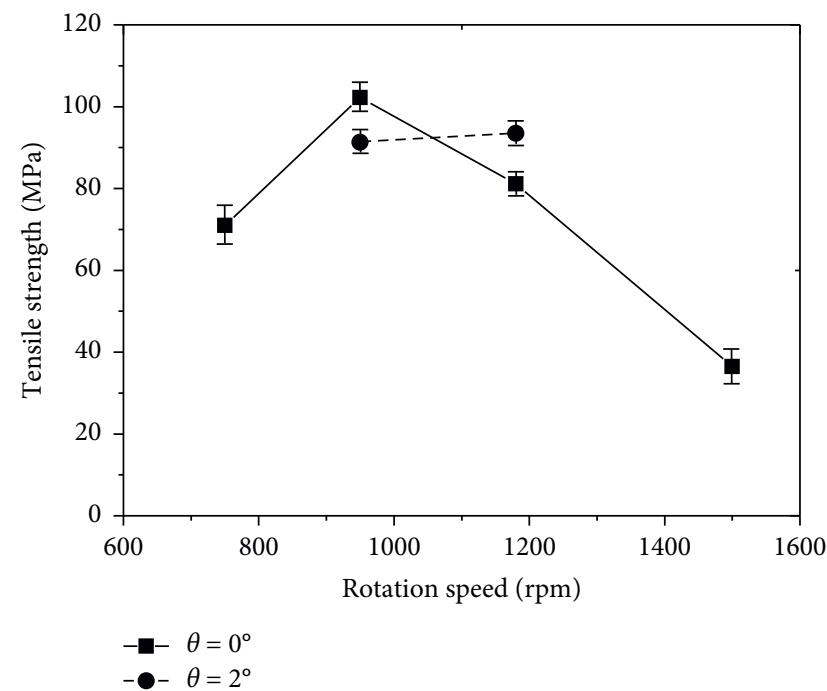

(a)

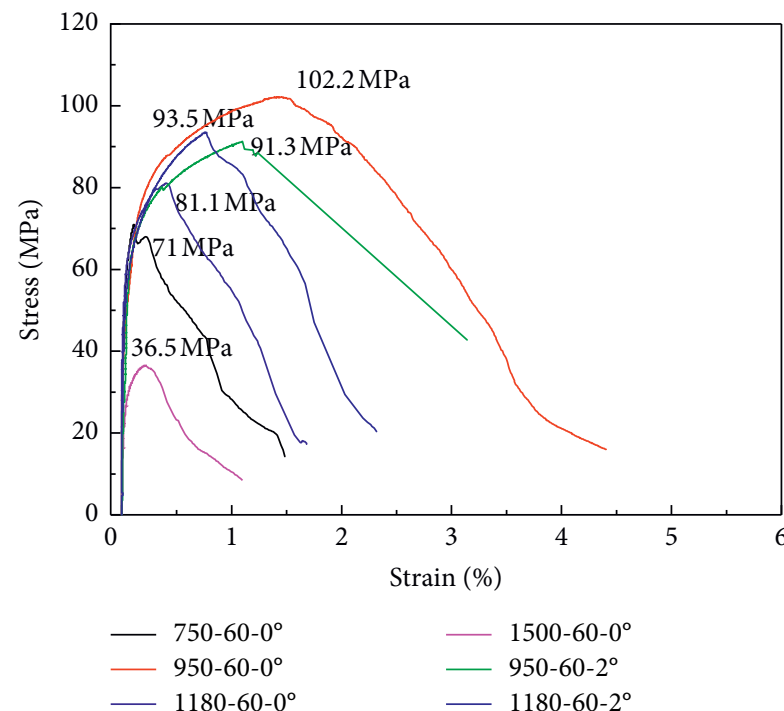

(b)

FIGURE 6: The joint strength and the typical stress-strain curve shown as (a) the strength of the joint procured by different parameter and (b) the corresponding stress-strain curves. 




(a)

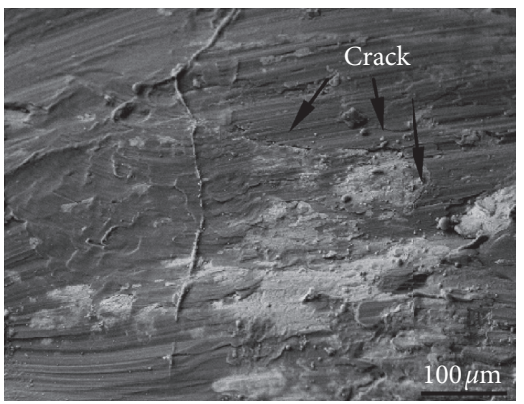

(d)

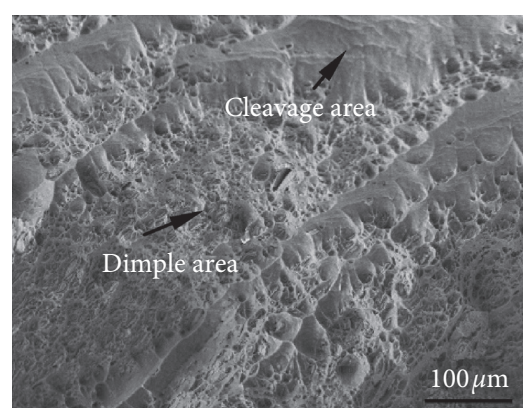

(b)

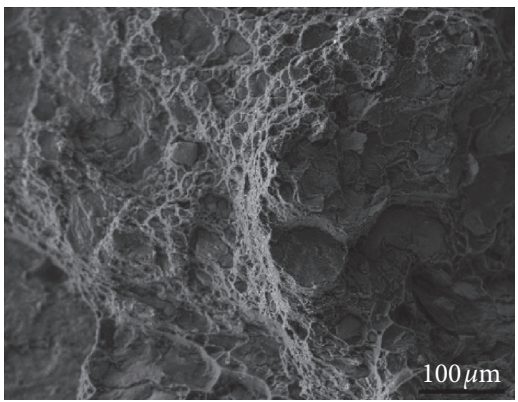

(e)



(c)

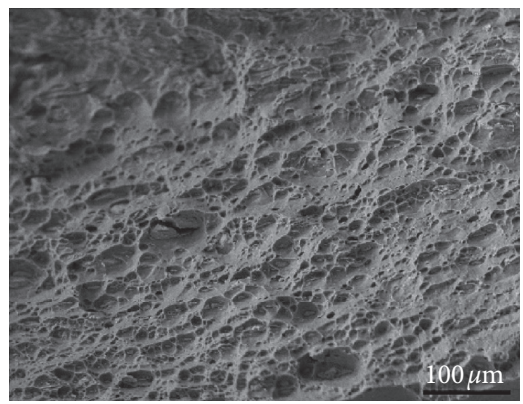

(f)

FIGURE 7: The fractured fracture morphology of the joints produced by (a) $750 \mathrm{rpm}-0^{\circ}$, (b) $950 \mathrm{rpm}-0^{\circ}$, (c) $1180 \mathrm{rpm}-0^{\circ}$, (d) $1500 \mathrm{rpm}-0^{\circ}$, (e) $950 \mathrm{rpm}-2^{\circ}$, and (f) $1180 \mathrm{rpm}-2^{\circ}$.

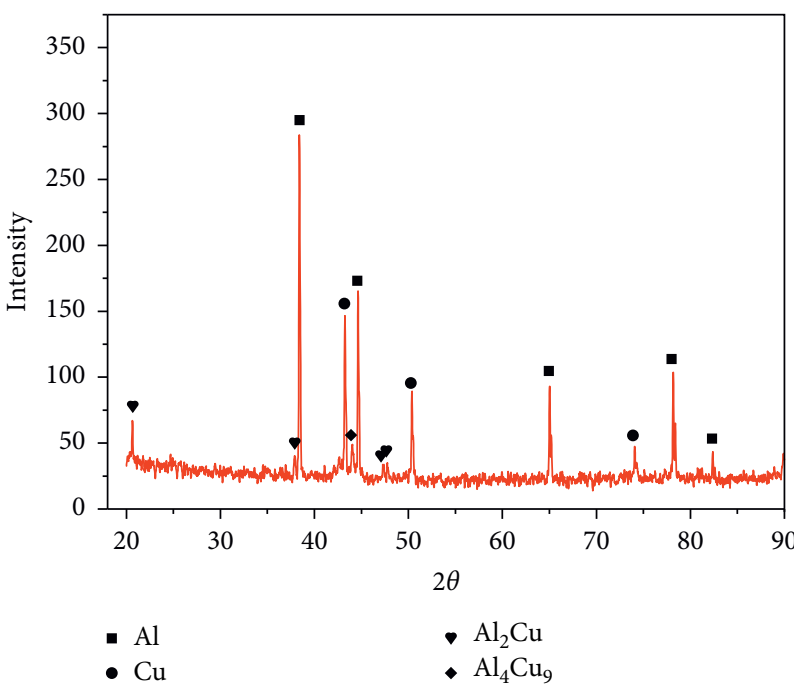

Figure 8: X-ray diffraction pattern of the fracture surface of the joint.

different positions of the joints is shown in Figure 10. The indentation at the compound was significantly smaller than that at the matrix under the same pressure.

3.3.2. Electric Conductivity of the Joint Al-Cu FSW. In this experiment, the resistivity was used to characterize the conductivity of the joint. The resistivity of the joint was estimated by the equation $\rho=R S / L$, where $R$ is the electrical resistance, $S$ is the sectional area, and $L$ is the specimen length. The TEGAM 1750 micrometer with a resolution for $0.1 \mu \Omega$ and the accuracy of $0.02 \%$ was used to test the resistance of the sample. The samples sizes for resistance test were $3 \mathrm{~mm}$ in diameter and $6 \mathrm{~mm}$ in length with aluminum and copper each accounting for half the volume. The resistivity of $\mathrm{Cu} / \mathrm{Al}$ bimetallic joint produced by FSW is shown in Figure 11. The theoretical resistivity of $\mathrm{Cu} / \mathrm{Al}$ heterogenic structures with same size was approximately $21.6 \times 10^{-9} \Omega \mathrm{m}$. The resistivity of the $\mathrm{Al}-\mathrm{Cu}$ FSW joint was lower or close to theoretical resistivity. It 


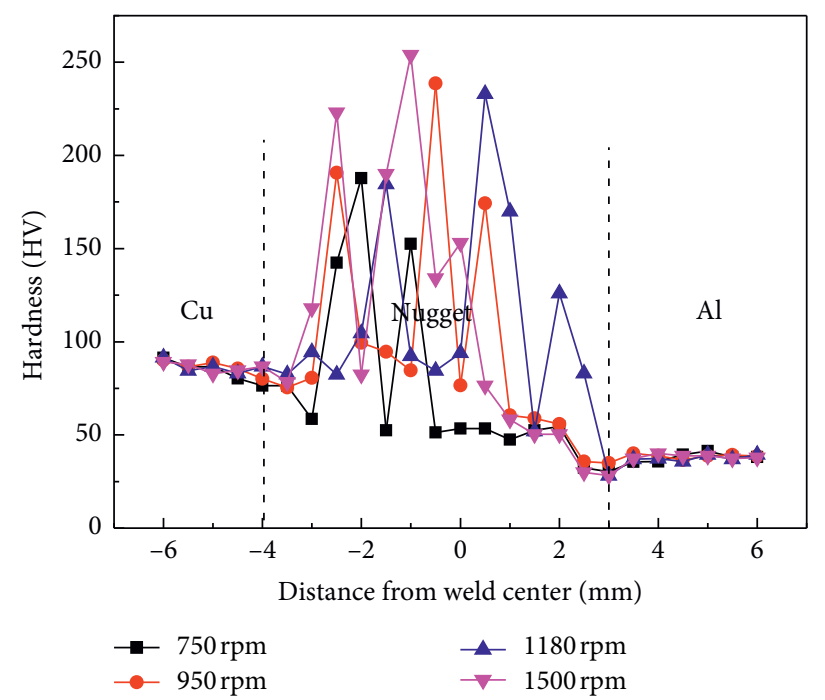

FIGURE 9: The microhardness distribution of joints at different rotation speeds.

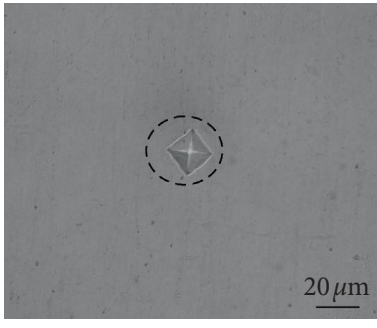

(a)

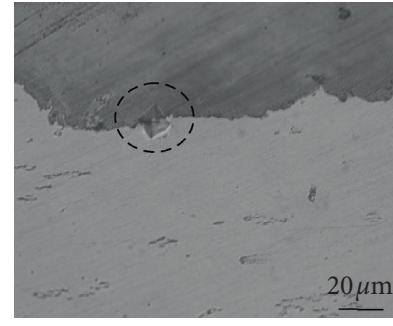

(b)

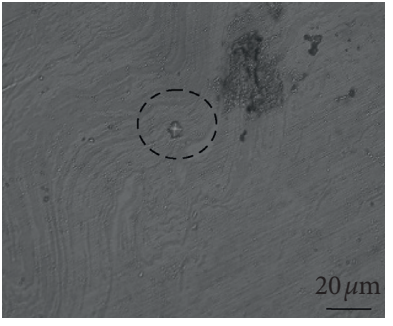

(c)

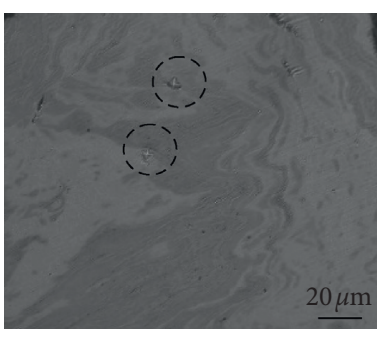

(d)

Figure 10: Microhardness indentation: (a) base material area; (b) Al-Cu interface; (c) (d) Al-Cu layered mixed area.

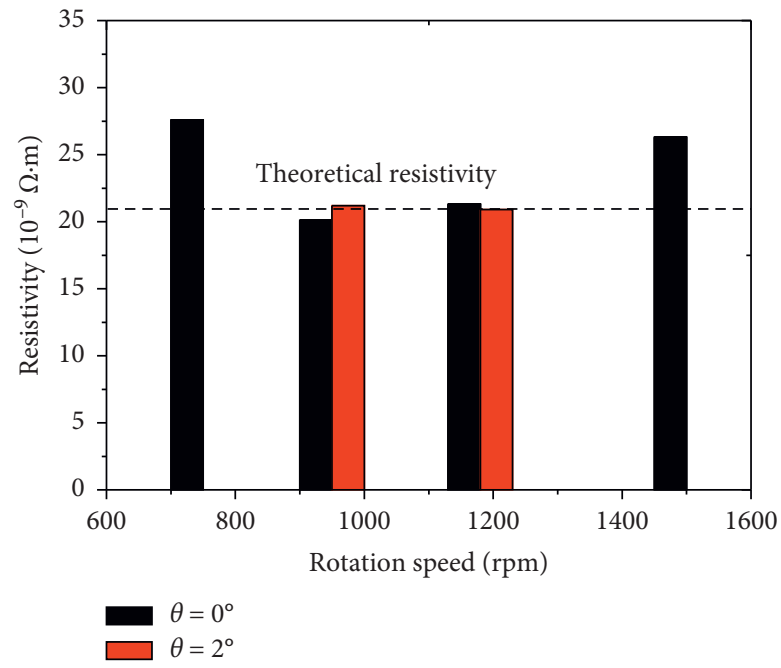

FIGURE 11: The resistivity of the Al-Cu FSW joint produced by different parameters.

indicated that the Al-Cu FSW joint has the referable conductive property.

Since $\mathrm{Cu}$ and $\mathrm{Al}$ are good conductive materials, the high resistivity of the interfacial transition layer was the main reason for the high resistivity of the joint, which determine the overall conductivity of the Al-Cu bimetallic composites structures. It is well known that interface defects and thicker compound layers exhibit poor conductivity. Table 3 shows the resistivity of $\mathrm{Al}, \mathrm{Cu}$, and intermetallic compounds. The resistivity of compounds is higher than that of the pure $\mathrm{Al}$ and $\mathrm{Cu}$ substrate. The interfacial resistance is directly affected by the joint defects, compound types, and thickness of 
TABLE 3: The hardness and resistivity of $\mathrm{Al}, \mathrm{Cu}$, and intermetallic compounds.

\begin{tabular}{lccc}
\hline Phase & $x(\mathrm{Cu}) \%$ & Hardness $\left(\mathrm{kg} \cdot \mathrm{mm}^{-2}\right)$ & Resistivity $(\Omega \cdot \mathrm{m})$ \\
\hline $\mathrm{Cu}$ & 100 & 90 & $1.75 \times 10^{-8}$ \\
$\mathrm{Cu}_{9} \mathrm{Al}_{4}$ & $62.5-69$ & 287 & $14.2 \times 10^{-8}$ \\
$\mathrm{Cu}_{3} \mathrm{Al}_{2}$ & $62.5-69$ & 557 & $13.4 \times 10^{-8}$ \\
$\mathrm{Cu}_{4} \mathrm{Al}_{3}$ & $55.2-56.3$ & 852 & $12.2 \times 10^{-8}$ \\
$\mathrm{CuAl}$ & $49.8-52.2$ & 1174 & $11.4 \times 10^{-8}$ \\
$\mathrm{CuAl}$ & $31.9-33.0$ & 735 & $8.0 \times 10^{-8}$ \\
$\mathrm{Al}$ & 0 & 40 & $2.83 \times 10^{-8}$ \\
\hline
\end{tabular}

the intermetallic compound layer. The thickness of the intermetallic compound layer at the $\mathrm{Al} / \mathrm{Cu}$ interface of $\mathrm{FSW}$ joints was within the range of $0.3-2.7 \mu \mathrm{m}$, so it has a lower interface resistance. Therefore, the defect-free joints of Al$\mathrm{Cu}$ FSW joint can achieve lower resistivity because it has a very thin compound layer compared with that of the other joining methods of $\mathrm{Al}-\mathrm{Cu}$.

\section{Conclusions}

In this paper, the FSW method was used to weld 1060 aluminum alloy and $\mathrm{T} 2$ copper with $4 \mathrm{~mm}$ in thickness. The influence of welding parameter on the microstructure and mechanical properties and electrical conductivity of the joint were investigated. The main conclusions are as follows:

(1) A well-formed Al-Cu FSW joint was successfully obtained. The cross-sectional morphologies of the $\mathrm{Al} / \mathrm{Cu} \mathrm{FSW}$ joints can be divided into three zones: the shoulder impact zone, the weld nugget zone, and the interface zone. The material flow shows parallel flow at the upper part and annular flow at the bottom.

(2) The interface zone consisted of metallurgical reaction layer and visible mixed structures. The reaction layers were identified as $\mathrm{Al}_{2} \mathrm{Cu}, \mathrm{Al}_{4} \mathrm{Cu}_{9}$ phases and the thickness of the IMC layer increased with the increase of the rotation speed.

(3) The tensile strength of the joints reaches maximum values of $102 \mathrm{MPa}$ at a rotation speed of $950 \mathrm{rpm}$ and inclination of $0^{\circ}$, which was approximately equal to that of $1060 \mathrm{Al}$ base metal. The fracture mechanism changed from a tough-brittle mixed fracture to brittle fracture as the rotation speed increases. The microhardness of the nugget zone was higher than that of the base metal and unevenly distributed. The Al-Cu FSW joints have a good conductivity.

\section{Data Availability}

The data used to support the findings of this study are included within the article.

\section{Conflicts of Interest}

The authors declare that they have no conflicts of interest.

\section{Acknowledgments}

This work was supported by the National Natural Science Foundation of China (Grant no. 51701154); the Key Research and Development Project of Shaanxi Province (Grant nos. 2017ZDXM-GY-033 and 2018ZDXM-GY-136); the China Postdoctoral Science Foundation-Funded Project (Grant no. 2016M592823).

\section{References}

[1] H. G. Kim, S. M. Kim, J. Y. Lee et al., "Microstructural evaluation of interfacial intermetallic compounds in $\mathrm{Cu}$ wire bonding with $\mathrm{Al}$ and Au pads," Acta Materialia, vol. 64, pp. 356-366, 2014.

[2] G. Huang, W. Hou, J. Li, and Y. Shen, "Development of surface composite based on Al-Cu system by friction stir processing: evaluation of microstructure, formation mechanism and wear behavior," Surface and Coatings Technology, vol. 344, pp. 30-42, 2018.

[3] V. Msomi, N. Mbana, and S. Mabuwa, "Microstructural analysis of the friction stir welded 1050-H14 and 5083-H111 aluminium alloys," Materials Today: Proceedings, vol. 26, pp. 189-192, 2020.

[4] H. A. Khan, K. Wang, and J. Li, "Interfacial bonding mechanism and mechanical properties of micro friction stir blind riveting for multiple $\mathrm{Cu} / \mathrm{Al}$ ultra-thin layers," Materials Characterization, vol. 141, pp. 32-40, 2018.

[5] T. Solchenbach and P. Plapper, "Mechanical characteristics of laser braze-welded aluminium-copper connections," Optics \& Laser Technology, vol. 54, pp. 249-256, 2013.

[6] Y. N. Wei, Y. G. Luo, H. T. Qu, J. T. Zou, and S. H. Liang, "'Microstructure evolution and failure analysis of an aluminum-copper cathode conductive head produced by explosive welding," Journal of Materials Engineering and Performance, vol. 26, pp. 1-9, 2017.

[7] J. Xiong, Y. Peng, H. Zhang, J. Li, and F. Zhang, "Microstructure and mechanical properties of $\mathrm{Al}-\mathrm{Cu}$ joints diffusionbonded with $\mathrm{Ni}$ or Ag interlayer," Vacuum, vol. 147, pp. 187-193, 2018.

[8] H. Xu, C. Liu, V. V. Silberschmidt et al., "Behavior of aluminum oxide, intermetallics and voids in $\mathrm{Cu}-\mathrm{Al}$ wire bonds," Acta Materialia, vol. 59, no. 14, pp. 5661-5673, 2011.

[9] W.-B. Lee, K.-S. Bang, and S.-B. Jung, "Effects of intermetallic compound on the electrical and mechanical properties of friction welded $\mathrm{Cu} / \mathrm{Al}$ bimetallic joints during annealing," Journal of Alloys and Compounds, vol. 390, no. 1-2, pp. 212-219, 2005.

[10] R. S. Mishra and Z. Y. Ma, "Friction stir welding and processing," Materials Science and Engineering: R: Reports, vol. 50, no. 1-2, pp. 1-78, 2005.

[11] K. Gangwar and M. Ramulu, "Friction stir welding of titanium alloys: a review," Materials \& Design, vol. 141, pp. 230-255, 2018.

[12] S. Ji, S. Niu, J. Liu, and X. Meng, "Friction stir lap welding of $\mathrm{Al}$ to $\mathrm{Mg}$ assisted by ultrasound and a $\mathrm{Zn}$ interlayer," Journal of Materials Processing Technology, vol. 267, pp. 141-151, 2019.

[13] X. Q. Lv, C. S. Wu, and G. K. Padhy, "Diminishing intermetallic compound layer in ultrasonic vibration enhanced friction stir welding of aluminum alloy to magnesium alloy," Materials Letters, vol. 203, pp. 81-84, 2017.

[14] A. Yazdipour and A. Heidarzadeh, "Effect of friction stir welding on microstructure and mechanical properties of 
dissimilar Al 5083-H321 and 316L stainless steel alloy joints," Journal of Alloys and Compounds, vol. 680, pp. 595-603, 2016.

[15] L. Zhou, M. Yu, B. Liu et al., "Microstructure and mechanical properties of $\mathrm{Al} /$ steel dissimilar welds fabricated by friction surfacing assisted friction stir lap welding," Journal of $M a$ terials Research and Technology, vol. 9, no. 1, pp. 212-221, 2020.

[16] H. Zhao, M. Yu, Z. Jiang, L. Zhou, and X. Song, "Interfacial microstructure and mechanical properties of $\mathrm{Al} / \mathrm{Ti}$ dissimilar joints fabricated via friction stir welding," Journal of Alloys and Compounds, vol. 789, pp. 139-149, 2019.

[17] P. Xue, D. R. Ni, D. Wang, B. L. Xiao, and Z. Y. Ma, "Effect of friction stir welding parameters on the microstructure and mechanical properties of the dissimilar Al-Cu joints," $\mathrm{Ma}$ terials Science and Engineering: A, vol. 528, no. 13-14, pp. 4683-4689, 2011.

[18] W. Zhang, Y. Shen, Y. Yan, and R. Guo, "Dissimilar friction stir welding of $6061 \mathrm{Al}$ to $\mathrm{T} 2$ pure $\mathrm{Cu}$ adopting tooth-shaped joint configuration: microstructure and mechanical properties," Materials Science and Engineering: A, vol. 690, pp. 355-364, 2017.

[19] P. K. Sahu, S. Pal, S. K. Pal, and R. Jain, "Influence of plate position, tool offset and tool rotational speed on mechanical properties and microstructures of dissimilar $\mathrm{Al} / \mathrm{Cu}$ friction stir welding joints," Journal of Materials Processing Technology, vol. 235, pp. 55-67, 2016.

[20] M. F. X. Muthu and V. Jayabalan, "Tool travel speed effects on the microstructure of friction stir welded aluminum-copper joints," Journal of Materials Processing Technology, vol. 217, pp. 105-113, 2015.

[21] H. Bisadi, A. Tavakoli, M. Tour Sangsaraki, and K. Tour Sangsaraki, "The influences of rotational and welding speeds on microstructures and mechanical properties of friction stir welded Al5083 and commercially pure copper sheets lap joints," Materials \& Design, vol. 43, pp. 80-88, 2013.

[22] N. A. Muhammad, C. S. Wu, and W. Tian, "Effect of ultrasonic vibration on the intermetallic compound layer formation in $\mathrm{Al} / \mathrm{Cu}$ friction stir weld joints," Journal of Alloys and Compounds, vol. 785, pp. 512-522, 2019.

[23] R. Beygi, M. Z. Mehrizi, D. Verdera, and A. Loureiro, "Influence of tool geometry on material flow and mechanical properties of friction stir welded Al-Cu bimetals," Journal of Materials Processing Technology, vol. 255, pp. 739-748, 2018.

[24] H. Schmidt, J. Hattel, and J. Wert, "An analytical model for the heat generation in friction stir welding," Modelling and Simulation in Materials Science and Engineering, vol. 12, no. 1, pp. 143-157, 2003.

[25] P. Xue, B. L. Xiao, D. R. Ni, and Z. Y. Ma, "Enhanced mechanical properties of friction stir welded dissimilar $\mathrm{Al}-\mathrm{Cu}$ joint by intermetallic compounds," Materials Science and Engineering: A, vol. 527, no. 21-22, pp. 5723-5727, 2010.

[26] M. Abbasi, A. Karimi Taheri, and M. T. Salehi, "Growth rate of intermetallic compounds in $\mathrm{Al} / \mathrm{Cu}$ bimetal produced by cold roll welding process," Journal of Alloys and Compounds, vol. 319, no. 1-2, pp. 233-241, 2001.

[27] A. Esmaeili, M. K. Besharati Givi, and H. R. Zareie Rajani, "Experimental investigation of material flow and welding defects in friction stir welding of aluminum to brass," $M a$ terials and Manufacturing Processes, vol. 27, no. 12, pp. 1402-1408, 2012.

[28] Q.-z. Zhang, W.-b. Gong, and W. Liu, "Microstructure and mechanical properties of dissimilar Al-Cu joints by friction stir welding," Transactions of Nonferrous Metals Society of China, vol. 25, no. 6, pp. 1779-1786, 2015. 